\title{
Astronomy Laboratory Experiences in the FullDome Digistar 5 Planetarium Environment
}

Shaukat Goderya ${ }^{1 *}$

\begin{abstract}
College level astronomy is typically offered as a laboratory-based introductory level course for non-science majors. In comparison to a typical physics laboratory where there is a large choice of equipment available for physics experiments, there is only a limited number of setups that can be used for nighttime astronomy activities. Furthermore, many astronomy events require time to collect data and this can be challenging in three-hour lab periods. Most instructors use a mix of different mediums like computer software, internet, and workbook style labs mixed with one or two optics experiments and a few stargazing activities with telescopes. These are all good methods to engage students in astronomy learning; however it cannot compare well with the actual process of collecting data by observing the night sky and analyzing that data. Certainly, it is possible to develop one or two such activities but for a variety of reasons it is not practical for a large class environment setting. Fulldome planetariums simulate the night sky and offer the ability to collect data on many astronomical events in a laboratory setting. Unfortunately, astronomy curriculum material that make use of fulldome technology in teaching and laboratory experiences in astronomy is largely lacking. The goal of this talk is to show that fulldome planetarium can be used as a medium for college-level astronomy courses. Several examples will be shown in which students collect and analyze astronomical data as well as activities that are planned for the future.

\section{Keywords}

Astronomy Education - Planetarium — Laboratory Activities

${ }^{1}$ Programs for Astronomy Education and Research, Tarleton State University, Stephenville, TX 76402

*Corresponding author: goderya@tarleton.edu
\end{abstract}

\section{Introduction}

When was the last time you visited a planetarium for a show? Today, modern planetarium facilities are fully immersive technologies and offer programming on variety of science subjects Law (2006), Yu (2005), Wyatt (2005). These facilities are equipped with the state-of-the-art fulldome video projections and surround sound audio systems. Some even offer 3D programming. Planetariums are expensive and they do not make profit from ticket sales un- like movie theaters. So how does an educational institute justify the cost of building a planetarium facility and continuous financial support it requires? The answer lies in the educational mission of the institution: to educate the students so that they play a positive role in the development of a country and its preservation through transfer of knowledge from one generations to the other.

At the heart of this mission is for the educational institution to provide an intellectual environment to students to develop their mental skills. Among the highest of mental skills to develop is problem solving. Science subjects allow students to build 
concrete-problem solving skills. The ability to solve problems starts with the act of observing and categorizing, and culminates in inferring, predicting and communication. Astronomy is an ideal science subject that lends itself to developing problem-solving skills. It is a subject that has been passed on from generations to generations and gets the highest level of interest from students. It appeals to all groups of people regardless of age, gender, or career goals. It is highly accessible in terms of learning concepts and content that are fundamental to everyone's life experiences, like the concept of time, calender, seasons, tides, and others. Further detailed discussion on the use of planetarium for education can be found elsewhere (see Smith and Haubold 1992; Reed 1994; Slater and Tatge 2017; Türk and Kalkan 2015; Bishop 1979; Riordan 1991).

Planetariums are ideal laboratories to learn and teach astronomy concepts. The first planetarium came into existence in October 21, 1923 in Deutsches Museum in Munich, Germany (Chartrand 1973, and Hagar 1973. Planetariums mimic the real night sky and offer an environment in which the simulated sky can be manipulated and experienced in real time. This very feature of the planetarium is the key to developing problem solving-skills in young minds. Consider the fact that in a typical laboratory experiment a student makes observations and/or measurements and carries out analysis of the data gathered to prove some known fact or law. For subject like physics and biology, there is a wealth of equipment and instruments available to make this possible in some prescribed, allotted time period. In astronomy, one usually uses a telescope at night for observations and measurements. There are many limitations that can make the learning experience challenging and difficult. For example, the weather is a big uncertainty, then there is the question of waiting until night time to do the activity and finally, many astronomical phenomena like moon phases require long periods of time to allow sufficient data gathering. This is where the planetarium provides the advantage. Activities can be done during the day time and the simulated sky can be manipulated for any time of future or past or changed in a step-wise manner.
The first planetarium at Tarleton State University was installed in 2001 with funding from the US Department of Education. It had Digistar II projection system with slide projectors and stereo sound system. Until 2014, the planetarium offered a variety of programming to the public, school districts and university community. However, like every other equipment, the Digistar II system became obsolete and difficult to maintain due to unavailability of slide projectors and parts and frequent breakdowns. The university administration decided to upgrade the equipment to Digistar 5 in 2015 (see Figure 1). However, that became a reality at the cost of some conditions, that, besides its entertainment value, the planetarium must be used by multidisciplinary classes for instructional activities and in particular, by introductory astronomy classes for instruction and laboratory experience. In this paper, I describe how the Tarleton planetarium is used for laboratory activities for introductory-level astronomy classes.

\section{Current Laboratory Activities in the Planetarium}

Eight laboratory activities have been developed that make use of the Digistar 5 projection equipment. Teaching assistants can run the planetarium equipment and so the activities are written in a general fashion and the worksheet contains enough information for teaching assistants such that no specific, separate instructor sheets are required. However, if needed, customized instruction sheets can be developed specific to one's planetarium facility. The activities list is as follows and a brief description of each is given below. Complete PDF files of activity worksheets cannot be provided in this proceeding paper in light of page requirements but can be made available upon email request. Here, only a few sample snapshots of some activities are shown to emphasize the data measurements, calculations, and analysis.

1. Constellations

2. Surface Brightness and Magnitudes

3. Celestial Sphere 


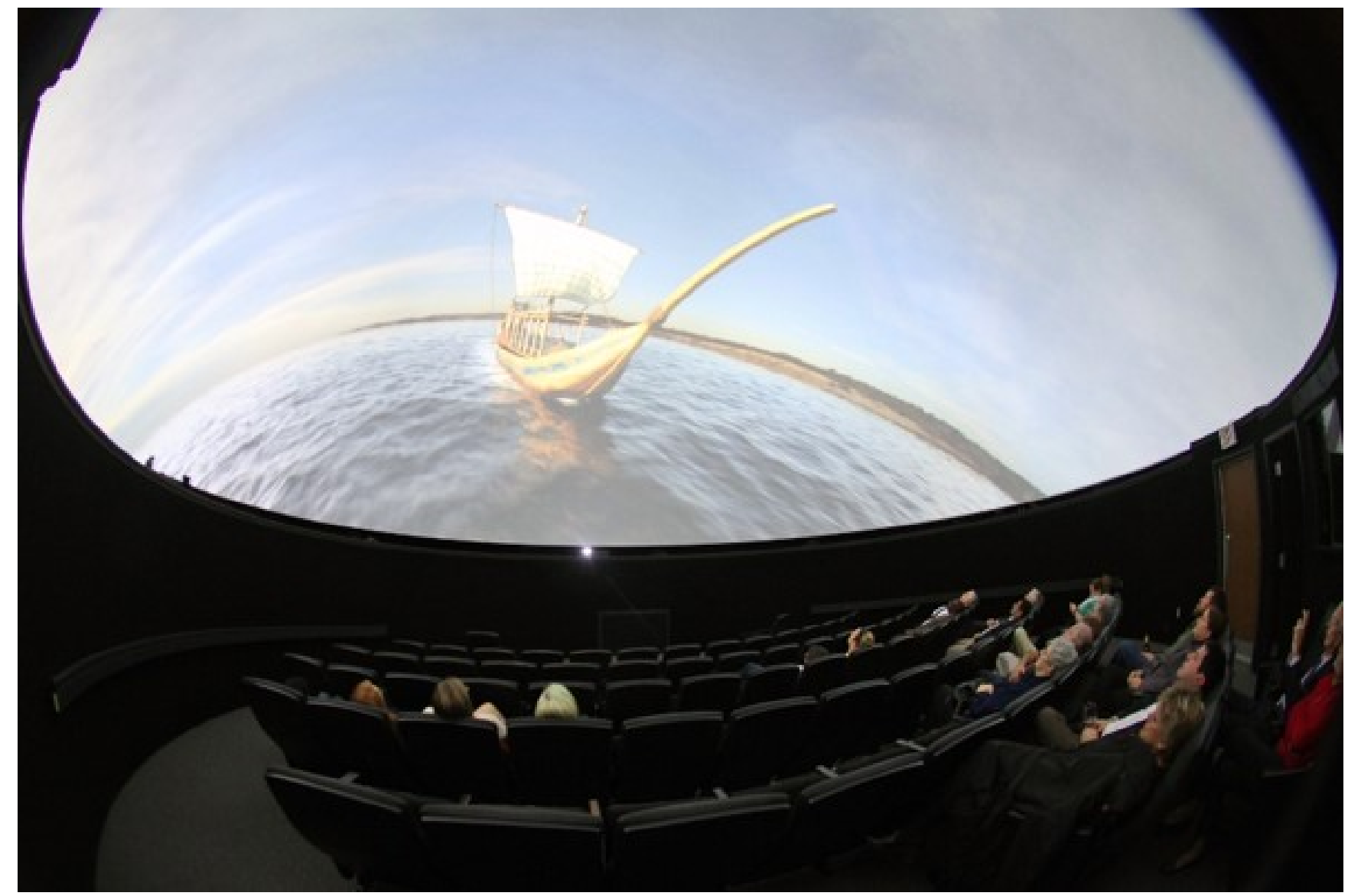

Figure 1. Tarleton Planetarium

4. Seasons

5. Lunar Phases

6. Kepler Laws

7. Precession

8. Cross Staff and Angle Measurements

\section{Constellations}

This laboratory activity focuses on five major objectives: 1) Learning to recognize major constellations of each season; 2) Finding Ursa Major, north pole and Polaris, with orientation in different seasons and the orientation of the Milky Way; 3) Learning some common asterisms with the help of charts; 4) Learning to predict when a certain bright star will rise or set; and 5) Comparing brightness and magnitude of stars in Ursa Maoris.

\section{Surface Brightness and Magnitudes}

In this activity students learn about different definitions that relate to brightness and magnitudes. The goals are: 1) To explore different types of twilight and its affects on star visibility, 2) Light pollution between a small city and a large city, and 3) Surface brightness of extended objects like nebulae and galaxies.

\section{Celestial Sphere}

This laboratory activity focuses on four major objectives: 1) Learning the names and location of major circles and season markers on the celestial sphere, 2) Learning to draw a celestial sphere and represent these circles and markers, 3) Learning and using the Altitude and Azimuth grid, and 4) Observing and recording the time, Altitude and Azimuth of the Sunrise, noon and Sunset on each equinox and solstice day.

\section{Seasons}

This activity has four major goals: 1) Learning to recognize the constellation of the Zodiac, 2) Learning the Right Ascension Declination grid system, 3 ) Recording the position of the Sun on the 21st of 
each month, more specifically, the azimuthal position at Sunrise and Sunset, the noon time altitude and declination of the Sun, and 4) Learning to plot a graph of altitude and declination as a function of time (21st of each month). From the data and graphs, students are asked a series of 15 questions to do simple calculations and determine the longest and shortest days and nights, obtain the tilt axis of the Earth, learn the significance of the tropic of Cancer and Capricorn lines on the Earth's map, predict the change in seasons that would occur if the tilt axis were to change. A snapshot of the table for collecting data is shown in Figure 2 and here are some sample questions. Readers who are interested in additional literature related to teaching seasons in the planetarium can refer to Yu et al. (2015).

1. Determine the amplitude of the curve in the graph you plotted. Show your calculations.

2. How does the amplitude compare (i.e. is it similar or different in value) to the Earth axis tilt of 23.5 degrees?

3. If the amplitude came out to be 90 degrees, what would seasons look like on Earth?

\section{Lunar Phases}

This activity has four major goals: 1) Understand the orbit of the Moon around Earth and the change it brings to the visibility of the Moon, 2) Learn to identify the phase of the Moon by observing it in the sky, 3) Learn the relationship between Moon phase, its rise and setting time and its position in the sky, and 4) Be able to predict future dates of various Moon phases. In the activity, students collect observational data over a full lunar month (see Figure 3). Following a series of example calculations, they complete calculations with their own data and answer a series of questions which are designed to help them learn how to predict the position, phase, and time of a certain lunar phase. Altogether, there are 15 questions in the activity, here are few example questions:

1. Compare your sketch for two last quarter moons, are they same or different? If so, in what respect they are different? Explain why?
2. Predict the date for the next new moon phase. What is it?

3. The Moon rises at $6 \mathrm{pm}$. What will be its altitude when it is on the meridian? Hint: see example 1.

\section{Kepler's Laws}

This activity has four major goals: 1) Learn the Kepler's laws of planetary motion, 2) Collect orbital period data on the four Galilean moons of Jupiter, 3) Learn how to compute the mass of planets by observing its natural satellites, and 4) Learn how astronomers estimate the size of our solar system using Kepler's laws. In a planetarium environment, the best way to identify the four moons of Jupiter is to show their orbital trace around the planet on the dome. Students collect the data for all the moons in their separate tables and then perform calculations to determine the mass of Jupiter with the help of four questions in the data analysis section.

\section{Precession}

This activity has three major goals: 1) Study the wobble motion of the Earth's spin axis, 2) Estimate the period of precession, and 3) Learn the observational changes in the sky, particularly as it applies to the north celestial pole. The students are shown the night sky at a present date and time and are asked to document their observations on the declination and altitude of a few properly chosen bright stars. They are then shown the night sky at a future date several thousand years later and asked to record the declination and altitude of the same brights stars again. Through a series of questions, students explore the changes precession brings about to circumpolar constellations, and estimate the period of precession.

\section{Cross Staff and Angle Measurements}

The objective of this activity is to measure angles in the sky by making and building a Cross-Staff. The goals are: 1) Design and build a Cross-Staff, 2) Use the Cross-Staff to make altitude and azimuth measurements of the Moon, and 3) Make angular measurements of the stars in the big dipper on a clear night sky and in the planetarium and compare 


\begin{tabular}{|c|c|c|c|c|c|c|c|c|}
\hline & A & B & C & D & $E$ & $\mathbf{F}$ & G & $\mathrm{H}$ \\
\hline $\begin{array}{l}\text { Date }-21^{\text {st }} \\
\text { day } \\
\text { Of Month }\end{array}$ & $\begin{array}{l}\text { Days } \\
\text { in } \\
\text { Month }\end{array}$ & $\begin{array}{l}\text { Number of } \\
\text { Days } \\
\text { passed }\end{array}$ & $\begin{array}{l}\text { Sunrise } \\
\text { Time }\end{array}$ & $\begin{array}{l}\text { Noon } \\
\text { Time }\end{array}$ & $\begin{array}{l}\text { Sunset } \\
\text { Time }\end{array}$ & $\begin{array}{l}\text { Altitude at } \\
\text { noon }\end{array}$ & $\begin{array}{l}\text { Declination } \\
\text { at noon }\end{array}$ & $F-G=X$ \\
\hline $\begin{array}{l}\text { January - } \\
2016\end{array}$ & 31 & 21 & & & & & & \\
\hline February & 29 & 52 & & & & & & \\
\hline March & 31 & & & & & & & \\
\hline April & 30 & & & & & & & \\
\hline
\end{tabular}

Figure 2. Sample Table for collecting data on Sun: Seasons Activity

the results. Figure 4 shows the material required to construct the Cross-Staff. Figure 5 shows the triangle used for trigonometry calculation. Figure 6 shows the table that is used in collecting data for the Moon.

\section{Activities Under Development}

Among the very best fundamental nighttime astronomy activities are to measure the magnitude of a pulsating and/or eclipsing binary star as a function of time and in comparison to nearby constant stars. However, most variable stars have period of the order of several hours and often one needs to be at a dark site to obtain data viable for plotting the light curve. In addition, weather uncertainty could make this a challenge not to mention the administrative increase in work for the instructor for very large classes. Now imagine if you could scale the period of the variable in the planetarium sky so that the required data could be collected in a couple of hours in a closed environment during night or day time. With Digistar 5, it should now be possible to implement variation of a known variable star against the background of nearby constant stars. While we do not have a working activity at the time of this writing however, efforts are underway to develop the necessary Digistar 5 scripts that can facilitate observation of a variable star in the planetarium.

\section{Discussion}

In this paper I have shown that it is possible to use the modern planetarium facility with Digistar 5 equipment to teach introductory astronomy and use it as a medium to offer several laboratory activities. These laboratory activities would be very challenging to do with large classes during night time and with the uncertainty of the weather conditions. Institutions and instructors that do not have Digistar 5 equipment but other systems or smaller mobile inflatable planetariums can easily adopt and modify these activities. Further, those who do not have any kind of planetarium facility can actually modify and adopt it to work with computer-based planetarium software like the freely available Stellarium. In fact, almost all of these activities were first tested with the Stellarium software during the development stage. All of the activities described in this proceeding paper are available to anyone under the Creative Common Attribution-NoncommercialShareAlike 4.0 International License. The author requests that people who use these laboratory activities in their astronomy classes provide feedback for improvement and any errors that are found. 
Year: 2018

\begin{tabular}{|c|c|c|c|c|c|c|c|c|c|}
\hline \multirow[t]{2}{*}{ Date } & \multicolumn{2}{|c|}{$\begin{array}{l}\text { Moon } \\
\text { Rise }\end{array}$} & \multicolumn{2}{|c|}{$\begin{array}{c}\text { Moon } \\
\text { Set }\end{array}$} & \multicolumn{5}{|c|}{ At Local Time } \\
\hline & Time & $\begin{array}{l}\text { Azimuth } \\
\text { in } \\
\text { degrees }\end{array}$ & Time & $\begin{array}{l}\text { Azimuth } \\
\text { in } \\
\text { degrees }\end{array}$ & $\begin{array}{l}\text { Local } \\
\text { Time }\end{array}$ & $\begin{array}{l}\text { Lit on } \\
\text { side (E, } \\
\text { W, } \\
\text { new, } \\
\text { Full) }\end{array}$ & Phase & $\begin{array}{l}\text { Elongation } \\
\text { in degrees }\end{array}$ & Phase appearance \\
\hline A & B & C & D & $\mathbf{E}$ & $\mathbf{F}$ & G & H & I & J \\
\hline Feb. 7 & $00: 47$ & 103 & $11: 50$ & 253 & 09:54 & $E$ & $\begin{array}{l}\text { Third } \\
\text { quarter }\end{array}$ & 235 & \\
\hline Feb 10 & & & & & 03:00 & & & & \\
\hline
\end{tabular}

Figure 3. Sample Table for collecting lunar data: Lunar Phase Activity

\section{Acknowledgments}

Thanks are due to Tarleton State University administration for making it possible to upgrade the planetarium equipment to Digistar 5. Thanks are also due to the planetarium staff for allowing me to teach astronomy in the planetarium and carry out the laboratory activities. Thanks are due to the creators of Stellarium, and sponsors and organizations that support the free software, without which it would have been difficult to test the content of the activities. Thanks are also due to Michigan astronomy program, a few of the activities were modeled on the planetarium based labs produced by the Michigan Astronomy and were made available under Creative common License. Finally thanks are also due to the department of Chemistry, Geoscience and Physics to provide teaching assistants to help implement the laboratory activities in my astronomy class.

\section{References}

Bishop, J. (1979). The educational value of the planetarium. The Planetarian, 8(1):7.

Chartrand, M. R. (1973). A Fifty Year Aniversary of a Two Thousand Year Dream, The History of the Planetarium. Planetarian, 2(3):95-101.

Hagar, C. (1973). The History of the Planetarium. The Planetarian, 2:111-15.

Law, L. E. (2006). Fulldome Video: An Emerging Technology for Education. Learning \& Leading with Technology, 34(3):12-15.

Reed, G. (1994). Who the Hell needs a Planetarium. Planetarian.

Riordan, R. (1991). Planetarium education: A re- 


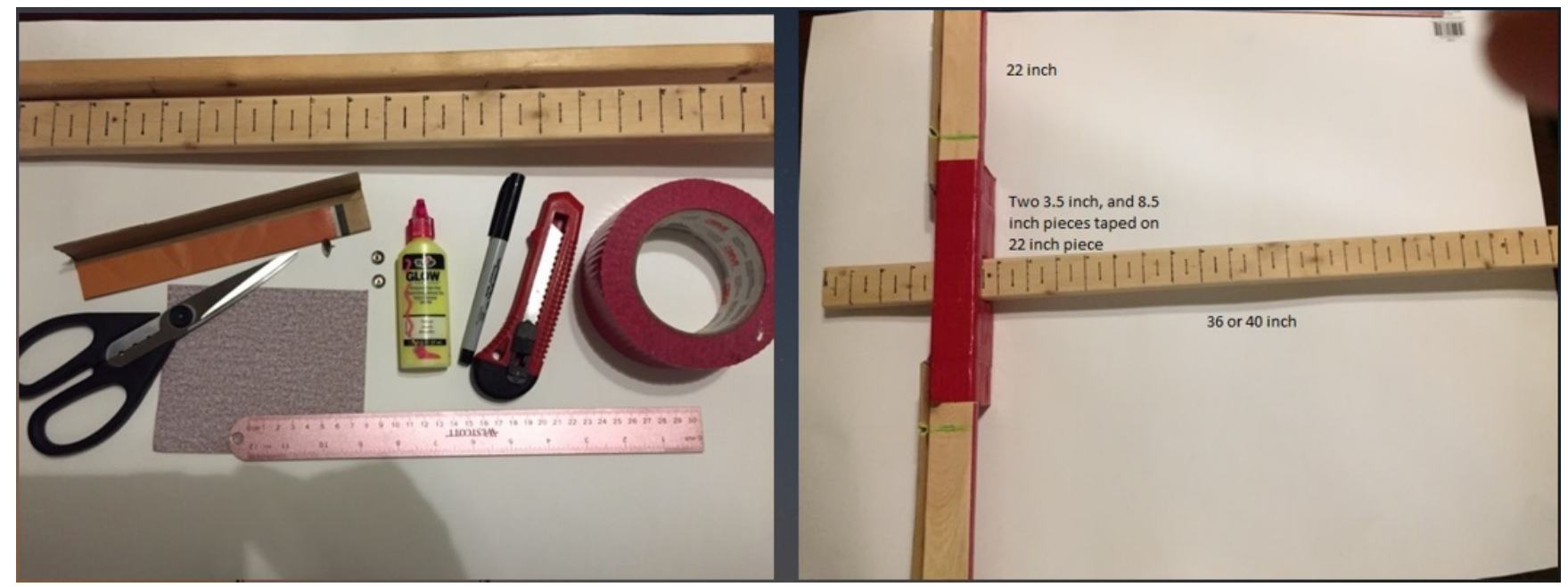

Figure 4. Materials for Cross-Staff

view of the literature. The Planetarian, 20(3):1825.

Slater, T. F. and Tatge, C. B. (2017). Research on Teaching Astronomy in the Planetarium. Springer.

Smith, D. and Haubold, H. (1992). Planetarium: a challenge for educators. United Nations, New York.

Türk, C. and Kalkan, H. (2015). The effect of planetariums on teaching specific astronomy concepts. Journal of Science Education and Technology, 24(1):1-15.

Wyatt, R. (2005). Planetarium paradigm shift. The Planetarian, 34(3):15-19.

Yu, K. C. (2005). Digital full-domes: The future of virtual astronomy education. Planetarian, 34(3):6-11.

Yu, K. C., Sahami, K., Sahami, V., and Sessions, L. C. (2015). Using a Digital Planetarium for Teaching Seasons to Undergraduates. Journal of Astronomy \& Earth Sciences Education, 2(1):3350. 


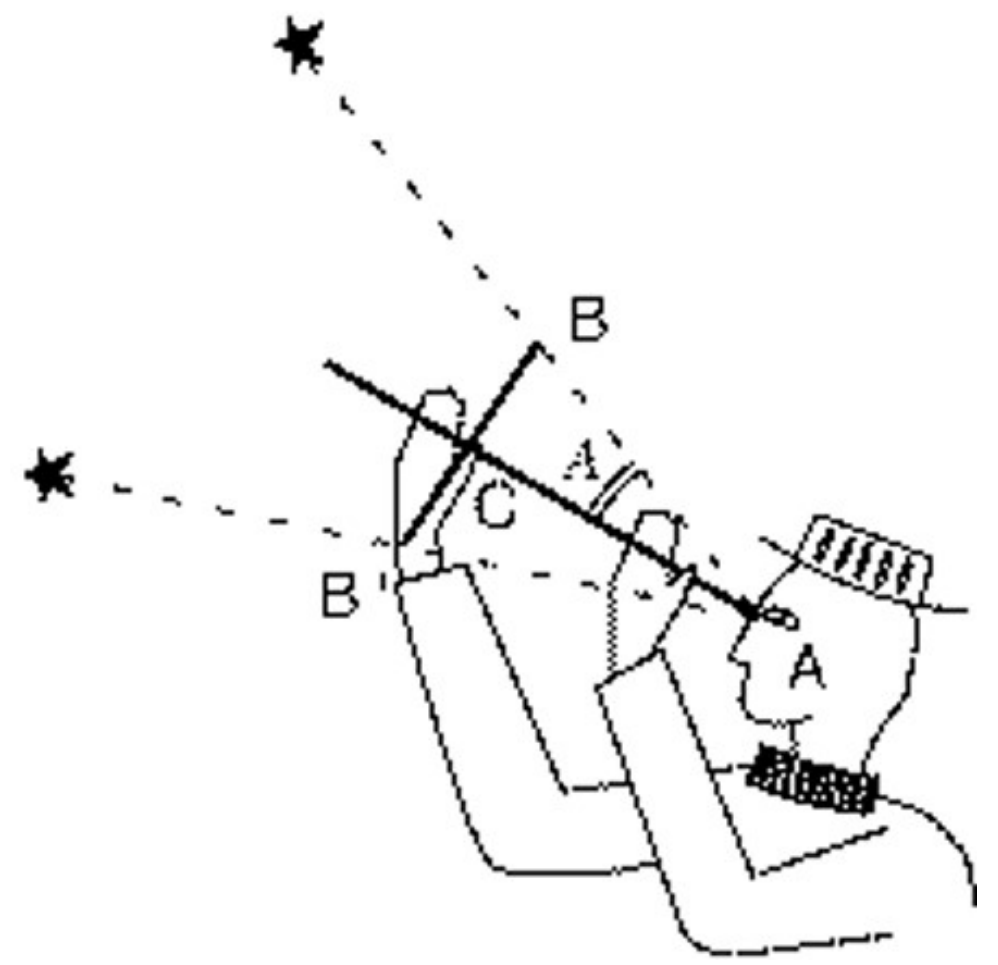

Figure 5. Triangle for Trigonometry calculations: Image source NASA

\section{Part I}

Use your cross staff to measure the altitude of the Moon and your smart phone compass to measure the azimuth for the following phases. If it happens to be cloudy or rainy during that day. Use the next day or a day earlier when it's clear the first chance. Also, if you have another engagement at that time, just do the observations couple of hours earlier or later.

\begin{tabular}{|c|c|c|c|c|c|c|}
\hline A & B & C & D & $\mathbf{E}$ & $\mathbf{F}$ & G \\
\hline Moon Phase & Day Number & BC & AC & A & $\begin{array}{l}\text { Moon's } \\
\text { Altitude }\end{array}$ & $\begin{array}{l}\text { Moon's } \\
\text { Azimuth }\end{array}$ \\
\hline $\begin{array}{l}\text { Waxing Crescent } \\
\text { October } 26^{\text {th }} \\
2017 @ 22: 00\end{array}$ & 5 & & & & & \\
\hline $\begin{array}{l}\text { First quarter } \\
\text { October } 27^{\text {th }} \\
2017 @ 17: 00\end{array}$ & 7 & & & & & \\
\hline $\begin{array}{l}\text { Waxing Gibbous } \\
\text { October } 31^{\text {th }} \\
2017 @ 22: 00\end{array}$ & 10.5 & & & & & \\
\hline $\begin{array}{l}\text { Full Moon } \\
\text { November } 4^{\text {th }} \\
2017 @ 00: 00\end{array}$ & 14 & & & & & \\
\hline $\begin{array}{l}\text { Waning Gibbous } \\
\text { November } 7^{\text {th }} \\
2017 \text { @ 06:00 }\end{array}$ & 17.5 & & & & & \\
\hline
\end{tabular}

Figure 6. Table for collecting data on Moon using a Cross-Staff 